\title{
COVID-19 Pandemic - Impact to Trauma and Orthopaedic services in a Northern Ireland District General Hospital
}

\author{
Matthews S*, McGoldrick P, Khan R, Bunn J
}

\author{
Department of Trauma and Orthopedics, Craigavon Area Hos pital, Northern Ireland
}

Received Date: May 1, 2021; Accepted Date: May 10, 2021; Published Date: May 19, 2021

"Corresponding author: Matthews S, Department of Trauma and Orthopedics, Craigavon Area Hospital, Northern Ireland. Tel: +447515155760; Email: wltrmt@aol.com

\section{Abstract}

In Northern Ireland our first lockdown began on 19th March 2020. The aim of this paper is to highlight the clinical response to the Covid 19 pandemic in a local district general hospital and compare orthopaedic trauma admissions requiring surgery during the period of the first national lockdown and that of the same period in the 2019. Data collected compared patient demographics, injuries, mechanism of injuries, operative management with the aim of highlighting local clinical response to changing demand on services and staff. The pandemic resulted in a 39\% reduction in orthopaedic admissions requiring surgery reflecting a change in public behaviour and BOAST Covid guidance. The learning points from this paper can help structure the response of other orthopaedic units in subsequent lockdowns and help predict how the trauma service may be impacted by a lockdown related change in demand.

\section{Background}

The first case of COVID-19 was confirmed in Northern Ireland on the $27^{\text {th }}$ February 2020, two months after the first confirmed case inWuhan, China [1]. Contact tracing identified the spread of the virus from Italy via Dublin Airport to Northern Ireland. Locally, our first death was reported just under three weeks later on the $19^{\text {th }}$ March 2020. Lockdown commenced locally on the $25^{\text {th }}$ March 2020.

The effects of this dynamic pandemic and how it would impact not only our health but working lives were unknown at that time and still are to a certain extent. As more research emerges it is paving the way for improved management strategies with ever evolving guidance being published [2-4]. Trauma workload can be an unpredictable service under 'normal' working circumstances. COVID-19 added another element of unpredictability to our local trauma service.

We changed how we managed the ongoing trauma requirement, and we addressed issues such a staffing and PPE during this challenging and risky time period. We were guided throughout by regular BOA corona virus pandemic guidelines [3], and PHA and NHS England updates [5].

The full impact and outcome both on our service and delivery of care was unknown and one that was completely unpredictable three months prior.

Craigavon Area Hospital (CAH) forms part of the Southern Health and Social Care Trust along with other hospitals including Daisy Hill Hospital in Newry, South Tyrone Hospital in Dungannon, St Luke's Hospital in
Armagh, and Lurgan hospital.It is a 450 bed DGH located 20 miles via motorway from Belfast city centre where the major trauma centre for Northern Ireland; the Royal Victoria hospital is located.

Two Emergency Departments (ED) normally service this geographical area along with minor injury units.COVID-19 brought the unexpected closure of Daisy Hill ED which then amalgamated with CAH ED along with subsequent redeployment of staff. The Trauma and orthopaedic service has a 28 bed trauma unit and a 23 bed elective Orthopaedic unit over two wards. It is staffed by $11 \mathrm{~T} \& \mathrm{O}$ Consultants, 3 Specialist Registrars, 5 Staff grade T\&O surgeons, 1 staff grade physician, 6 Middle Grade doctors and 2 F1s.

\section{Aim}

To highlight the impact to our local Trauma service delivery to compare our admission and surgical procedure profile between 1st March and 31st May 2020 to historical admissions and surgical procedures over a similar period in 2019.

\section{Pre-COVID 19}

Our service delivery varied greatly before the pandemic, adapting to service demand and resources provision. The biggest variable was the delivery of Trauma services. The service delivery in the year prior to the pandemic is detailed below (Table 1). CAH serves a population of 360,000 people from the boroughs/districts of Craigavon, Banbridge, Armagh, Dungannon-South Tyrone, Newry and Mourne. There are 28 in patient trauma surgery beds and 23 inpatient elective surgery beds available. Daily there was one trauma surgery list conducted and two elective surgery lists conducted. There was space allocated at the end of each elective surgical list to allow trauma cases to be completed if there was a requirement. This was generally the case during the warmer months. If the presenting trauma cases were such that the allocated time on the elective surgical list was not required, it would be utilised for elective surgery. There was a fracture clinic and an orthopaedic clinic on site on a daily basis at CAH. We also conducted off site fracture clinics in Daisy Hill hospital. Precovid clinic schedule as shown in (Table 1) below. 


\begin{tabular}{|c|c|c|c|c|c|}
\hline Day & Monday & Tuesday & Wednesday & Thursday & Friday \\
\hline \multirow{3}{*}{ Morning } & $\begin{array}{l}1 \text { Orthopedic } \\
\text { clinic on site }\end{array}$ & $\begin{array}{l}1 \text { Orthopedic } \\
\text { clinic onsite }\end{array}$ & $\begin{array}{l}2 \text { Orthopedic } \\
\text { clinic onsite }\end{array}$ & $\begin{array}{l}1 \text { Orthopedic } \\
\text { clinic onsite }\end{array}$ & $\begin{array}{l}1 \text { Orthopedic } \\
\text { clinic onsite }\end{array}$ \\
\hline & $\begin{array}{l}1 \text { Fracture } \\
\text { clinic onsite }\end{array}$ & \multirow[t]{2}{*}{$\begin{array}{l}1 \text { Fracture } \\
\text { clinic onsite }\end{array}$} & \multirow[t]{2}{*}{$\begin{array}{l}\text { 1 Fracture } \\
\text { clinic onsite }\end{array}$} & \multirow[t]{2}{*}{$\begin{array}{l}1 \text { Fracture } \\
\text { clinic onsite }\end{array}$} & \multirow[t]{2}{*}{$\begin{array}{l}1 \text { Fracture } \\
\text { clinic onsite }\end{array}$} \\
\hline & $\begin{array}{l}1 \text { Fracture } \\
\text { clinic offsite }\end{array}$ & & & & \\
\hline \multirow{3}{*}{ Afternoon } & $\begin{array}{c}2 \text { Fracture } \\
\text { clinic on site }\end{array}$ & $\begin{array}{l}1 \text { Orthopedic } \\
\text { clinic on site }\end{array}$ & $\begin{array}{l}1 \text { Orthopedic } \\
\text { clinic on site }\end{array}$ & $\begin{array}{l}2 \text { Orthopedic } \\
\text { clinic on site }\end{array}$ & \multirow{3}{*}{$\begin{array}{l}1 \text { Fracture } \\
\text { clinic onsite }\end{array}$} \\
\hline & \multirow[t]{2}{*}{$\begin{array}{l}1 \text { Orthopedic } \\
\text { clinic on site }\end{array}$} & $\begin{array}{l}1 \text { Fracture } \\
\text { clinic onsite }\end{array}$ & \multirow[t]{2}{*}{$\begin{array}{l}1 \text { Fracture } \\
\text { clinic onsite }\end{array}$} & \multirow[t]{2}{*}{$\begin{array}{l}1 \text { Fracture } \\
\text { clinic onsite }\end{array}$} & \\
\hline & & $\begin{array}{c}1 \text { Fracture } \\
\text { clinic offsite }\end{array}$ & & & \\
\hline
\end{tabular}

Table 1: Presentation of weekly clinics.

\section{Trust COVID-19 Response \&Adaptions to Practice}

Each regional trust had a different response to the outbreak of Covid-19 to adapt to local needs. In the Southern Trust with immediate effect on March $13^{\text {th }}$ the local elective service was postponed. This included all elective operating lists and clinics appointments.

\section{ED Site specific Adaptions}

The Trust aimed to centralise Emergency services and there was a temporary suspension of service at the emergency department in Daisy hill Hospital and a rapidly set up second emergency department on the grounds of CAH. This was designed so that there were two separate emergency departments; one for patients with respiratory symptoms and one for those presenting with other ailments. These were designated the "Covid" Emergency Department and the "NonCovid" emergency department. The additional aim of centralising emergency care was that patients were being admitted only from one site. On diagnosis they could be streamed to beds on different sites across the Trust. Those who tested negative for Covid-19 could potentially be transferred to Daisy hill inpatient beds for further care with the aim of creating a "Covid free" hospital. Those patients with symptoms or who tested positive for Covid-19 who would remain as inpatients on the Craigavon site. As trauma services remained on the $\mathrm{CAH}$ site, all patients requiring admission to trauma wards were admitted to side rooms on the $\mathrm{CAH}$ site and isolated initially until Covid status was obtained. A negative test permitted normal trauma ward care; and patients with a positive test were managed on a Covid ward.

\section{T\&O Site Specific Adaptions}

The trust implemented an immediate suspension of elective work and changed the role of the elective orthopaedic ward of 23 beds made up mainly of single side rooms into a Covid "holding ward". All patients with Covid symptoms awaiting medical or surgical care were admitted awaiting swab results before transfer to specialty wards.

The 8amTrauma meetings where admissions and theatre lists for the day were presented had only essential persons in attendance - the medical staff on take the previous day, the medical staff coming onto take and the medical staff operating in theatre. The Weekly trauma review meeting where all trauma operations of the previous week were peer reviewed and learning discussed was suspended.

In order to reduce the footfall of patients in hospital, fracture clinics were overhauled and patients managed in accordance with BOA emergency guidance [3-4]. Patients were managed with removable splints where appropriate; radiographs were obtained remotely, at peripheral sites and telephone reviews of patients performed where safe to do so. Patients attending fracture clinic were gathered at specific appointments times in main waiting room area with socially distanced with seats; with other areas marked off not to be used. Patients were invited into the clinical areas when space for them to be seen immediately was available.
Fracture clinic referrals and review appointments were screened by a consultant and footfall on the hospital grounds was reduced as much as possible with only the patients needing to be seen in person invited to attend clinic. The remaining patients were given 'virtual' reviews - a telephone consultation at a given time combined with an $\mathrm{x}$-ray, if required, performed at a remote site.

The aim of these interventions was to prevent unnecessary patient footfall and reduce close healthcare staff contact during a rapidly escalating global pandemic. This protected both the health of patients and healthcare workers. It also stopped those patients encountering other members of the public had they presented to hospital.

A new 'front of house' minor injury assessment was initiated where any patient presenting to the emergency department with an injury confirmed to be a fracture was sent directly to fracture clinic to be further assessed and managed by the trauma team. This allowed early intervention by a specialist team by way of appropriately moulded casts, and splint age. This removed an initial fracture clinic review, and encouraged 'get it right first time' in accordance to BOAST guidance [3].

In an evolving trauma strategy, out of hours was covered by a registrar or speciality doctor and a senior house officer on site who provided advice and attended for reductions of fractures and application of moulded casts where required in the ED.

The weekly arthroplasty meeting was suspended. A daily service planning meeting was had with all present consultants and other attending remotely with the Heads of service to plan and adapt service delivery to the evolving Covid situation.

\section{Staff Specific Adaptions}

A "Pod System" was developed and implemented 30/3/20, 15 days after lockdown began within the Trauma unit in response to local guidance. Consultants and Trainee Registrars/ Middle Grade doctors were separated into two teams who worked independently in a week on/ week off basis in order to ensure that if an outbreak of Covid-19 occurred with the trauma team that only half of the main clinical team would be affected. The aim of this strategy was to lower levels of staffing to a minimum while still maintaining an adequate and safe trauma service to the trust while protecting staff from unnecessary potential exposure to Covid-19 patients. During an "off" week doctors were allowed to cross-cover the "on" team members who were unwell or self-isolating with symptoms of Covid-19.

Foundation Year 1 staff were re deployed to medical wards on 30/3/20 to help alleviate the burden on medical staff as a result of the COVID admission surge. This resulted our departmental SHOs giving medical cover to the trauma wards throughout the day and out of hours.

Areas in the hospital were risk stratified with a traffic light system as per PHA and IPC guidelines: 
- $\quad$ Green - No PPE required.

- Amber - Fluid shield mask and visor - gloves and apron for patient contact.

- $\quad$ Red - Full PPE with FFP3 mask non-sterile surgical gowns and non-sterile gloves.

Admin areas were assigned green, ward environments with low risk patient's assigned amber and ICU, Theatre and respiratory wards assigned red [6].

Important for trainees working within the department, trauma operating theatre time were reduced, audit meetings were suspended, teaching suspended and journal club cancelled. Conferences nationally were also suspended.

\section{Predictions}

The prediction was made within the trauma and orthopaedics team that the effects of nationwide lockdown would result in a reduction in the number of patients presenting with fractures to the emergency department and a tendency to more conservative management strategies of fractures and therefore a reduction in the number of operations performed for fracture management during the lockdown period [7-11]. To what degree services would be impacted was unknown during these uncertain, unprecedented and challenging times. This paper analyses the operations carried out during the period of lockdown between March and May 2020 and compares those to operations carried out during the same period between March and May 2019. We aim to understand better the changes to operative management of fractures within the Southern Trust as a result of service changes and lockdown measures.

\section{Methods}

Inclusion criteria were three months of trauma admissions data and operations were retrospectively collected over March, April and May of 2019 and 2020. This was done using our in house daily excel spreadsheets for admissions and operations and cross referencing with our online theatre management system (TMS) and Northern Ireland Electronic Care Record (NIECR). Once the data was collated it was summarised into average age, age ranges, mechanisms of injury, injuries sustained and operations performed for each of the three months in each year and then tallied together for an overall total for each year also.

There were no exclusion criteria.

\section{Results}

\section{Admission Numbers}

Compared to the 479 admissions +/- operations we had 2019 in the months of March, April and May we seen a 39\% reduction in overall numbers to 291 , The individual month breakdown was similar per month in each of the two years year being a 31\% drop in March, $46 \%$ in April and $40 \%$ in May, (see figure 1 below).

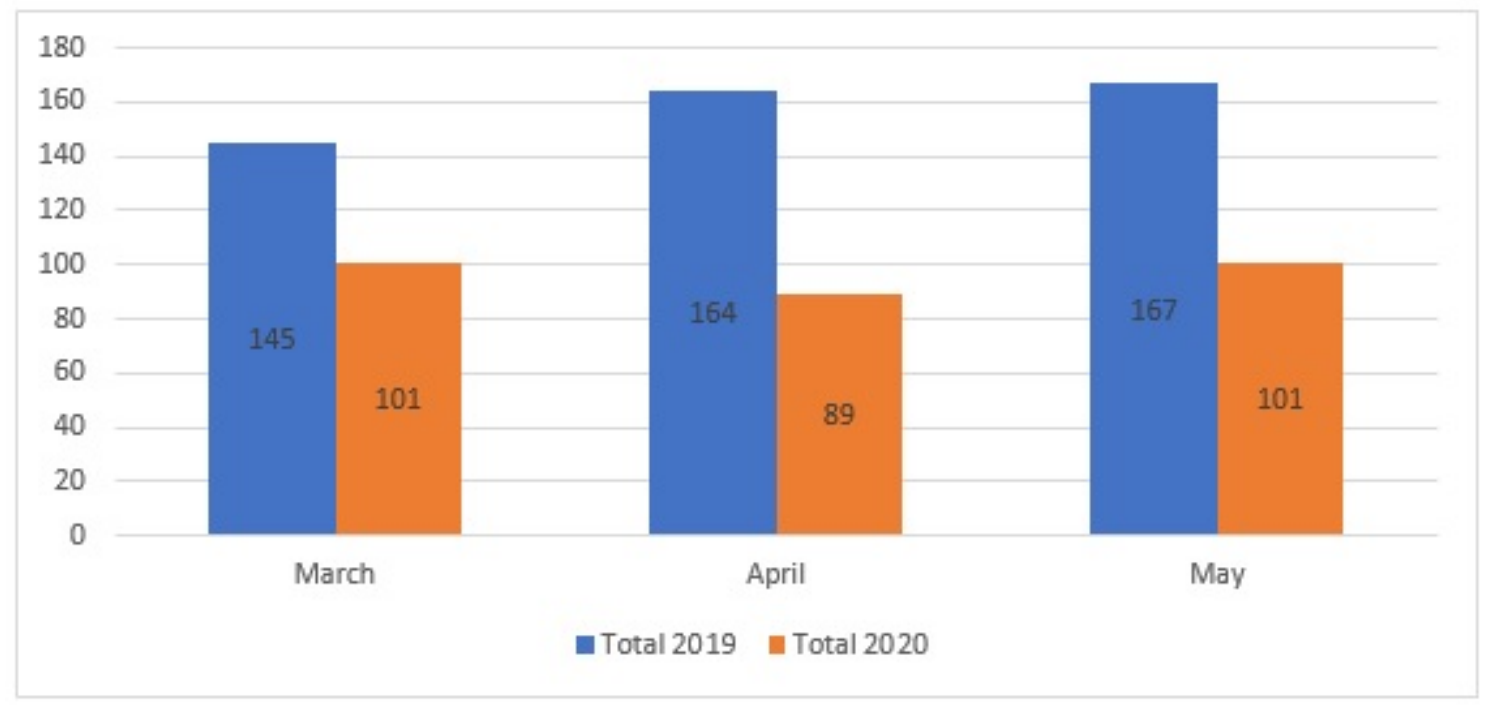

Figure 1: Monthly breakdown admissions march, April and May 2019 v 2020.

\section{- Admission Age Profile}

The mean age increased from $55+/-2.1$ (range 14-97) to 64+/2.5 (range 14-95) across this 3 month period. There is a statistical increase in the mean age of all patients admitted requiring an operation, $\mathrm{p}<0.05$

\section{- Gender Demographics}

\begin{tabular}{|c|c|c|c|}
\hline & $\mathbf{2 0 1 9}$ & $\mathbf{2 0 2 0}$ & Total \\
\hline Male & 248 & 127 & 375 \\
\hline Female & 231 & 164 & 395 \\
\hline Total & 479 & 291 & \\
\hline
\end{tabular}

Table 2: Demographics.

As shown in (Table 2) above, 2019 saw more males than females with M:F ratio of $1.07: 1$ whereas 2020 was the converse with a F:M ratio of 1.29:1 This was statistically significant with chi square testing $\mathrm{p}=0.0286$ significance 0.05 Males seen a $49 \%$ reduction in overall admission whereas females reduced by $29 \%$ to the above figures. The average age of patients admitted with a fractured neck of femur (NOF) was $78.4+/-1.90(\mathrm{n}=116$, range 51-96) in 2019 and $80.5+/$ $1.80(\mathrm{n}=112$, range $47-96)$ in 2020 , which is not statistically significant (using T test) (see Figure 5).

The mean age of admission for all other fractures represented a statistically significant increase $(\mathrm{p}<0.05)$ from $48.0+/-2.20$ $(\mathrm{n}=367$, range $15-97)$ in 2019 to $53.1+/-3.10(\mathrm{n}=179$ range 12-96) in 2020.

Numbers of fractures admitted in all ages up to 80 decreased across all 3 months in 2020 compared to 2019. However, the number of people in the age ranges of 81-90 and 90+ increased in all 3 months in 2020 compared to 2019 (see Figure 2). 


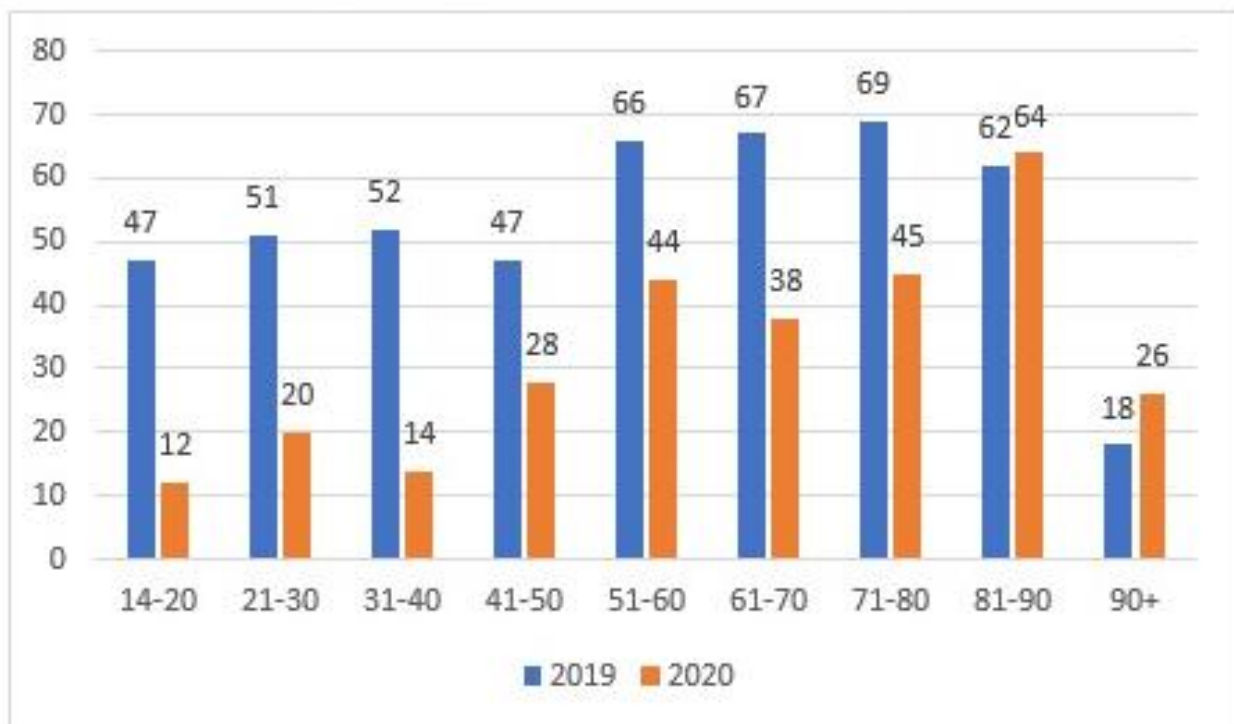

Figure 2: Total age range numbers March-May 2019 v 2020.

Injuries: Total Injuries collated were down 39\% from 488 to 298.

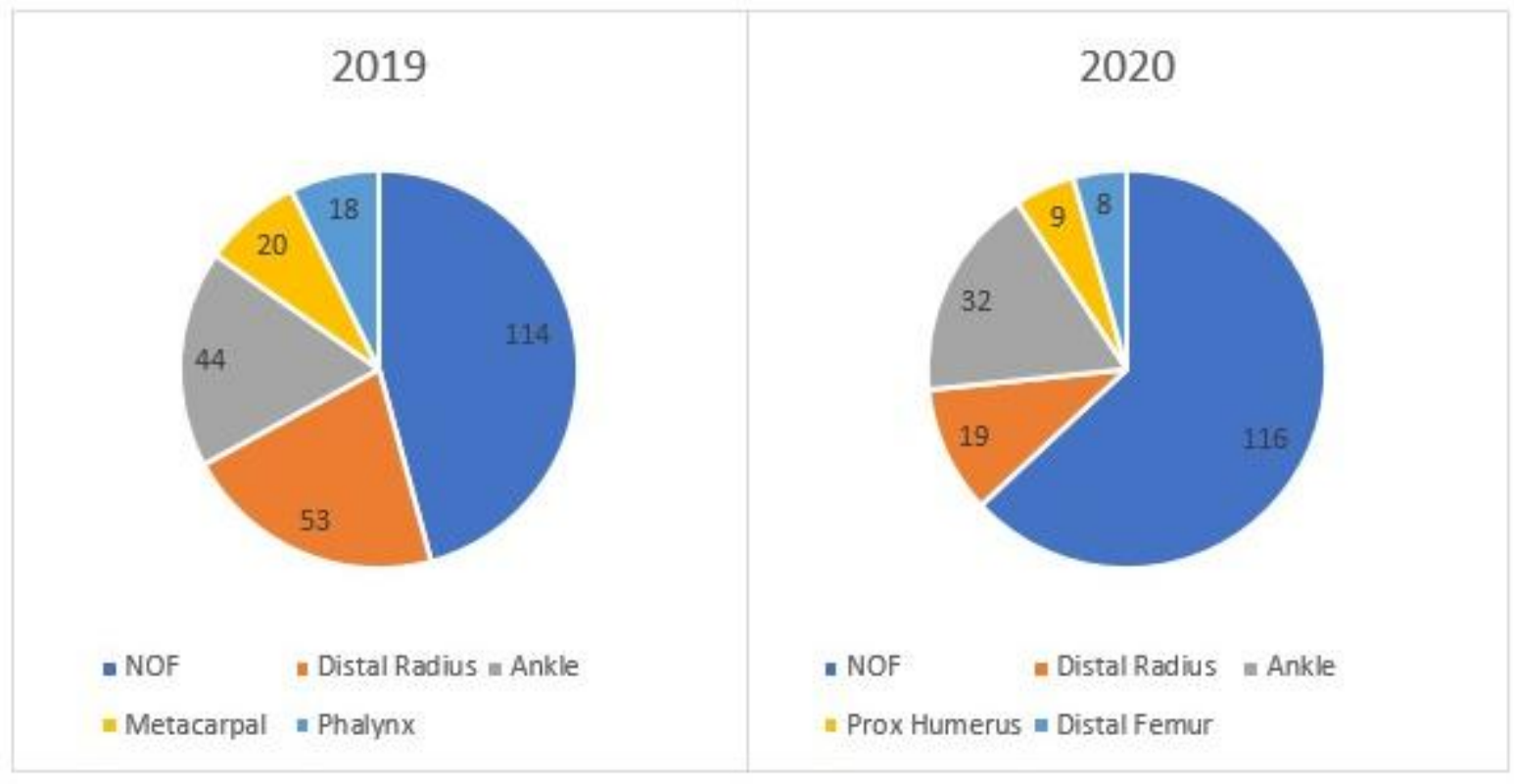

Figure 3: Top 5 injuries admitted to CAH 2019 v 2020.

The most common injury over each month was NOF followed by Ankle and Distal Radius in 2020 but the reverse in 2019 with distal radius being more prevalent NOF numbers increased by $2 \%$ with Ankle fractures falling by $27 \%$ and distal radius by $54 \%$, all highlighted in (figure 4 and 5) with injuries which remained the same between the comparative years shown below in (Table 3).

\begin{tabular}{|c|c|}
\hline Injuries & $\mathbf{2 0 1 9} / \mathbf{2 0 2 0} \mathbf{n}=$ \\
\hline Tib/Fib & 8 \\
\hline Distal Humerus & 5 \\
\hline Vertebral \# & 2 \\
\hline Foreign Body & 1 \\
\hline Open Distal Humerus & 1 \\
\hline Open Forearm & 1 \\
\hline Open Phalynx & 2 \\
\hline
\end{tabular}

Table 3: Injuries with same overall total number 2019 v 2020 . 


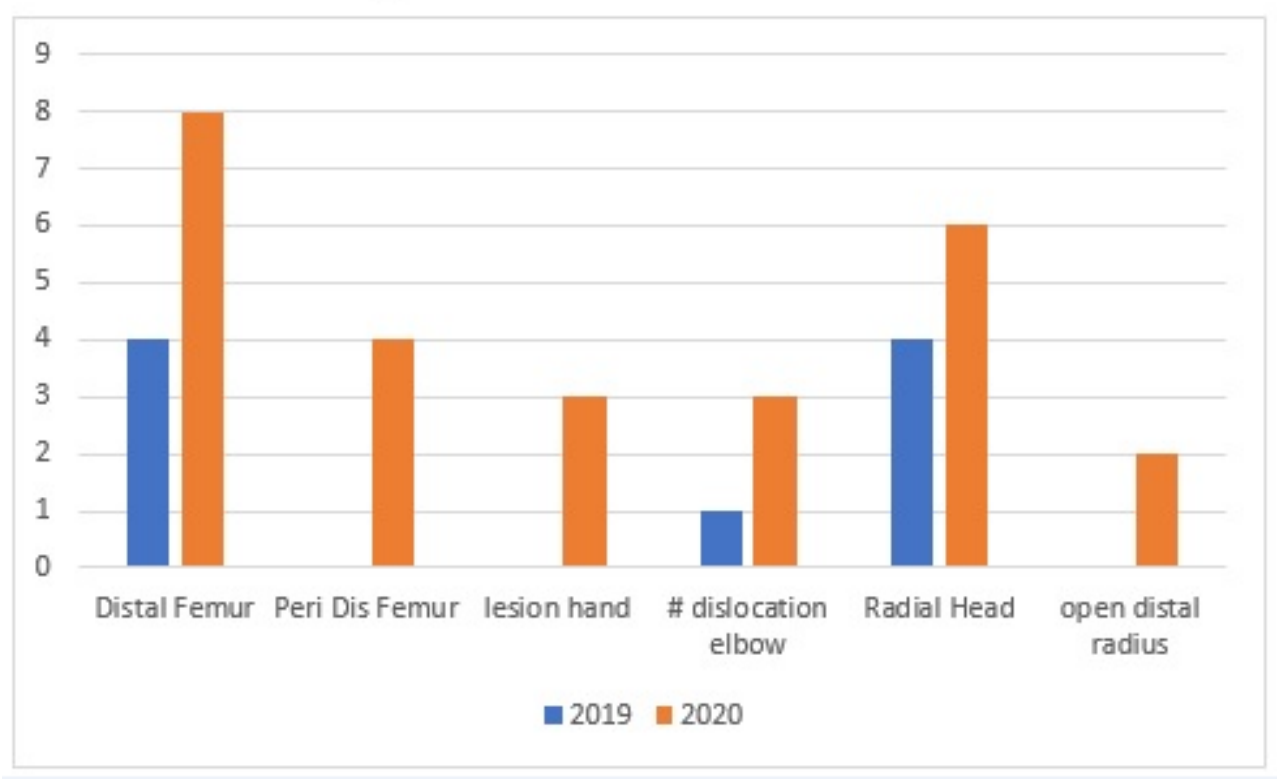

Figure 4: injuries (excluding neck of femur fractures) that increased in overall number in 2020 compared to 2019.

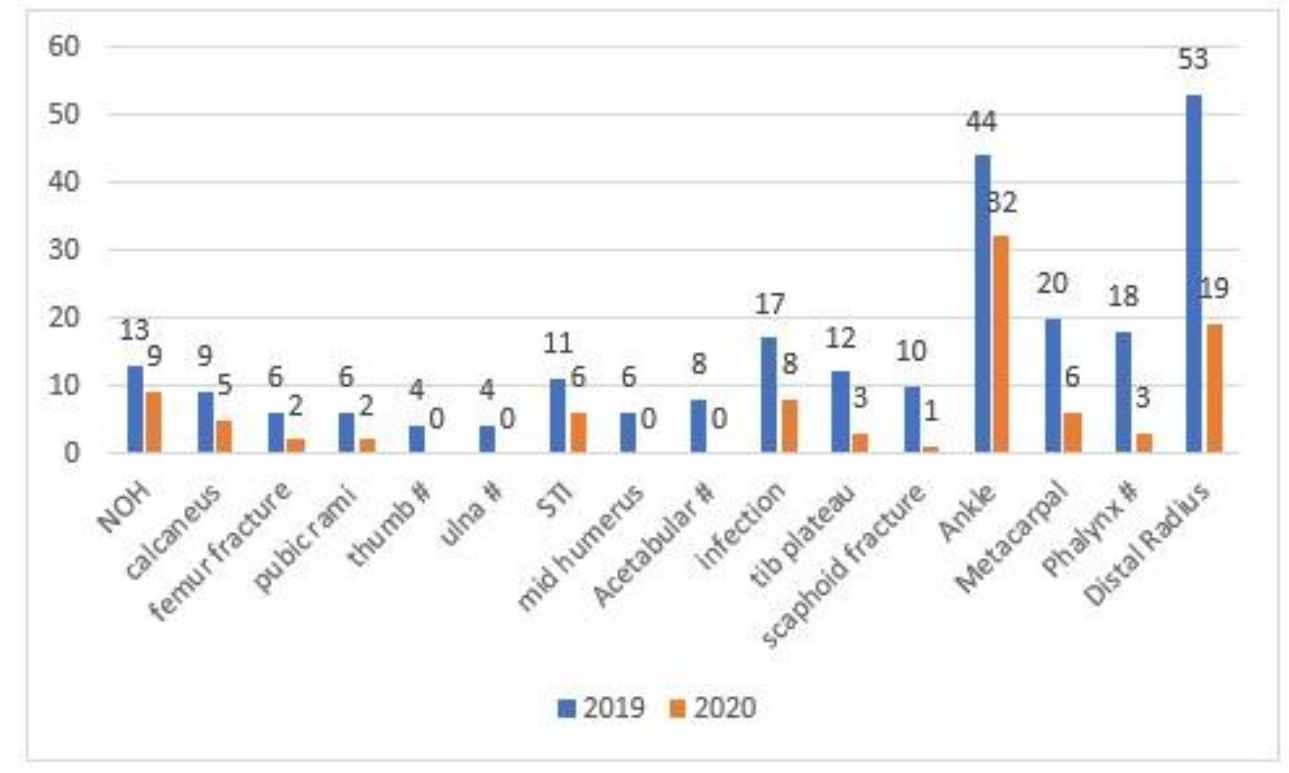

Figure 5: operative injuries with largest reduction in numbers March-May 2019 v 2020 range -34 to -4 .

\section{Operations}

Operations were also down $38 \%$ from 435 to 271. Admitted conservatively managed injuries dropped by $49 \%$ from 41 to 20 - lower threshold for not admitting patients without a clear necessity given the risk. The top 5 operations in both years across the 3 month period were the same but in a varied order. The top operation was Hip Hemiarthroplasty each year. In 2019 this was followed by Ankle ORIF, DHS, Distal radius ORIF and long gamma nail. In 2020 this was followed by DHS, Ankle ORIF, long gamma nail and Distal radius ORIF as shown below in table 4 and figure 6 with operations with the largest reduction between comparison years shown in (figure 7).

\begin{tabular}{|c|c|c|}
\hline Operation & $\mathbf{2 0 1 9} \mathbf{n}=$ & $\mathbf{2 0 2 0} \mathbf{n}=$ \\
\hline Hemiarthroplasty & 44 & 45 \\
\hline Ankle ORIF & 33 & 31 \\
\hline DHS & 29 & 31 \\
\hline Distal Radius ORIF & 28 & 15 \\
\hline Long Gamma NAil & 23 & 18 \\
\hline
\end{tabular}

Table 4: operation numbers - top 5 most performed 2019/2020. 


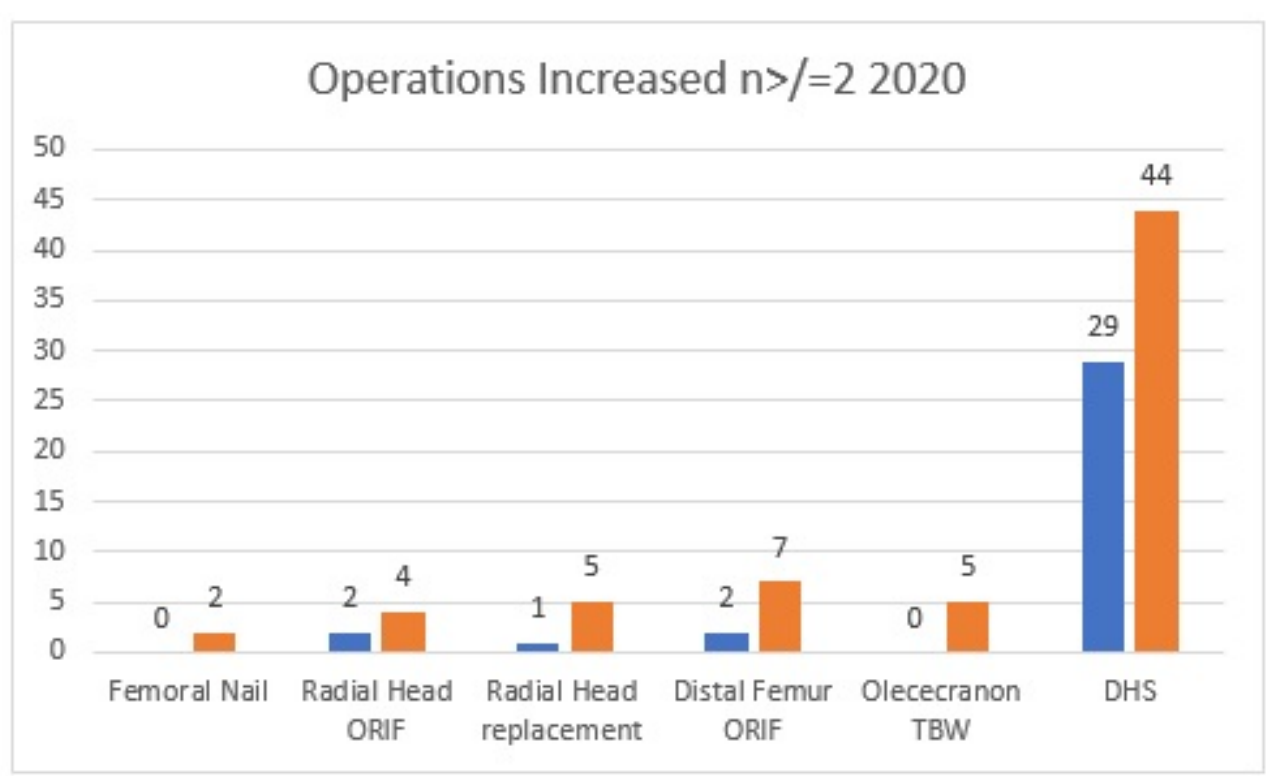

Figure 6: operations with an increase in numbers>2 2019 v 2020.

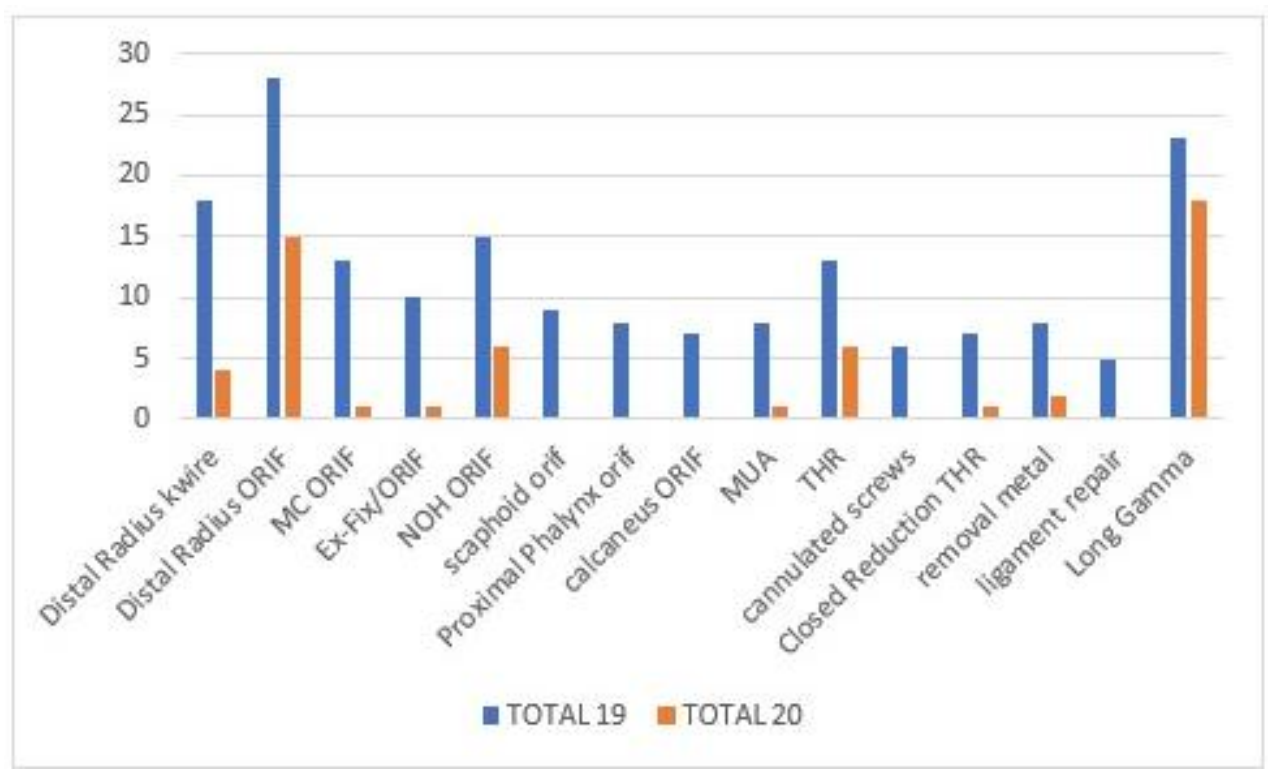

Figure 7: operations with biggest reduction in numbers 2019 v COVID-19 range -14 to -5 .

\section{Mechanisms}

- The below mechanisms all increased or remained static, (see figure 23).

- Those that increased included pathological, fall. $.0 .5 \mathrm{~m}$, fall of a step, fall $>3 \mathrm{~m}$.

- Those that remained static included fall $>1 \mathrm{~m}, \mathrm{RTC}$, fall $>4 \mathrm{~m}$ and seizure.

- This was despite at 39\% reduction in mechanisms from 479 in 2019 to 291 in 2020 highlighted in figures 8,9,10.

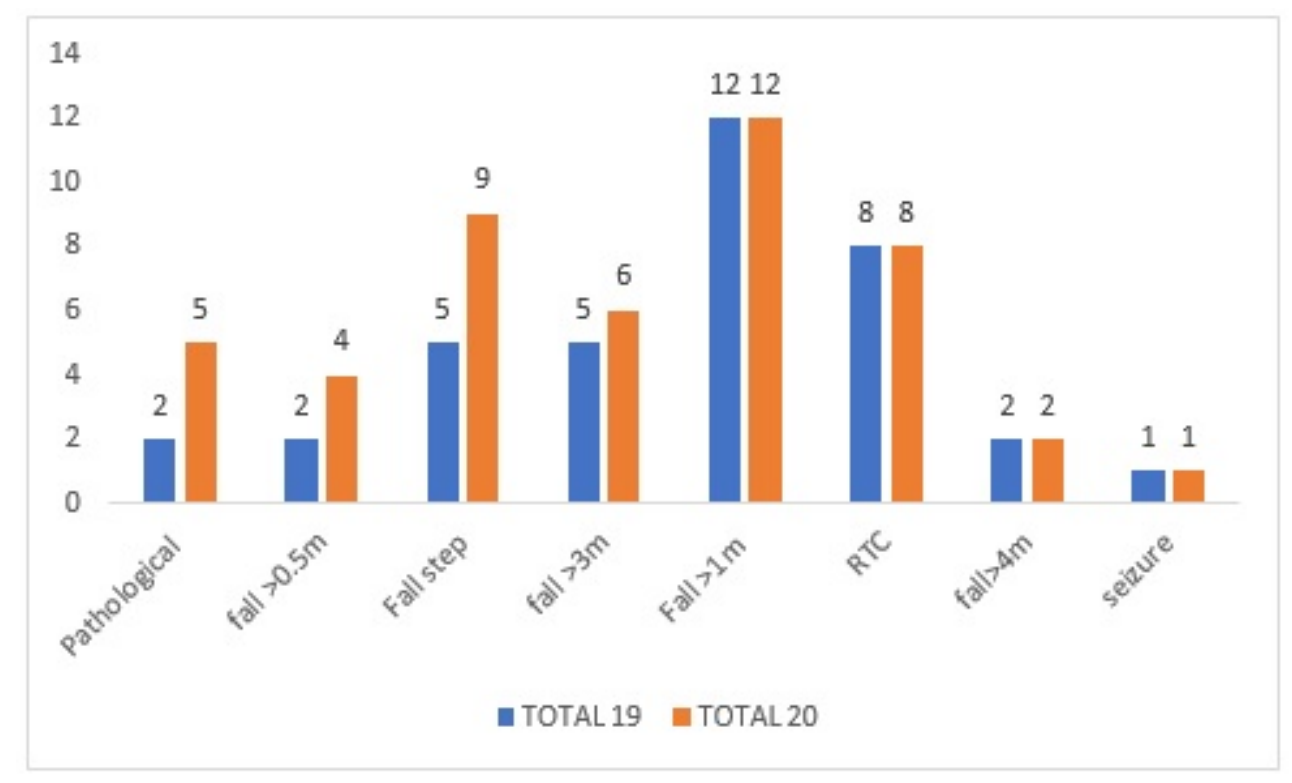

Figure 8: mechanism of injuries 2019 v 2020 - increased and constant. 


\section{Top 5 Mechanisms}

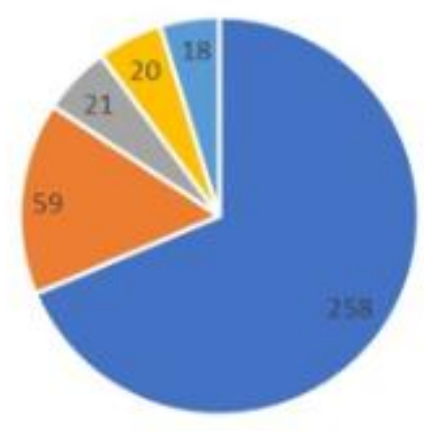

- Fall Standing $=$ Fall height $=$ football = atraumatic =crush

\section{Top 5 Mechanisms}

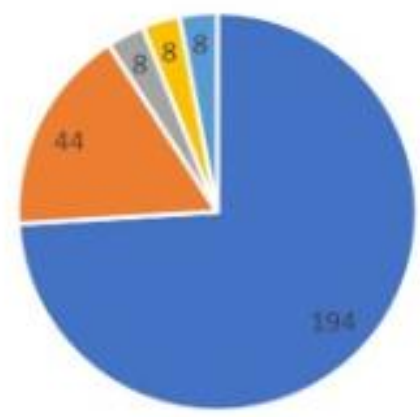

- Fallstanding = Fall height = RTC " Crush = Atraumatic

Figure 9: The top 5 mechanisms in each year.

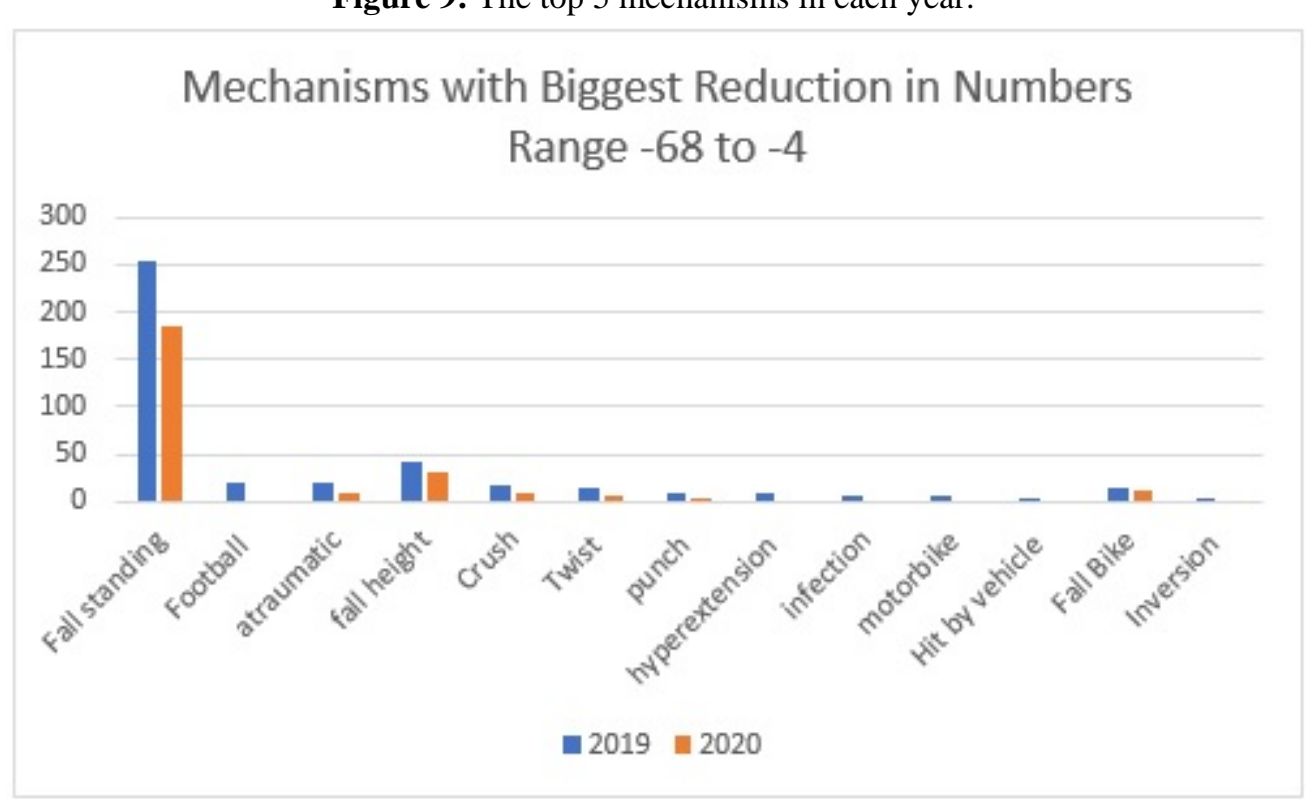

Figure 10: top 10 mechanisms with largest reduction overall numbers range -68 to -6 .

\section{Discussion}

There is a clear statistical significance to suggest that there was a decreased presentation of fractures requiring surgical intervention within the Southern Trust. Given the dramatic reduction in fractures requiring surgery during this first regional lockdown, the clinical adaptations made in line with national COVID guidance allowed us to maintain a safe and efficient delivery of trauma services for both patients and staff. Similar studies published throughout the UK mainland and Ireland reflects similar results as shown here [7-8].

\section{Admissions}

The data shows a significant reduction of trauma admissions and operations by 39\%over 3 months March-May this decrease appears to be in the younger age groups which lockdown will have directly impacted by a reduction of people socialising, more people working at home, no sport. Therefore, the risk of injury requiring admission is less according to our study through lockdown as we predicted it would be. We did not expect the impact to be as significant however.

Age

The average age of admission increased from 55 to 65 during the 3-month period of data collection in 2019 and 2020 
respectively. This was not reflected however in the mean age of patients presenting with hip fractures (intra capsular and extra capsular fractures of neck of femur) where the mean age of presentation rose from 79 to 80 years between 2019 and 2020 date collections which did not show statistical significance. The non NOF fracture mean age increased from 48 to 54 which brought the average age up but the proportion that NOF represented out total injury load increased from 23 to $39 \%$ which will have impacted on our overall total mean age increase also. Lockdown we believe has less of an impact on the older generation compared to the younger population since the overwhelming majority of NOF in our elderly cohort were fall from standing height in the home which will happen irrespective of lockdown or not. The average rise in non NOF mean age as previously mentioned is likely due to the lockdown being imposed decreasing the options for leisure, sport and work activities in which mainly younger people affected are affected. The increase the older age ranges above 80 may have reflected lockdown status where help from carers, family and friends was reduced or suspended resulting in elderly people having to attempt more relative risk with activities of daily living which they otherwise may have had help with.

\section{Injuries}

As in figure 6above there was an increase in injuries associated with falling from height between 2019 and 2020 such as distal femur fracture $(+4)$, periprosthetic distal femur fracture $(+4)$, fracture dislocation elbow $(+2)$, radial head fracture $(+2)$ and open distal radius fracture $(+2)$. Injuries with no change in overall numbers between 2019 and 2020 included; Tibia and fibula fracture, distal humerus fracture, vertebral fractures, foreign body removal, open distal humerus fracture, open toe phalynx fracture, open hand phalynx facture, open forearm fracture Injuries which decreased between 2019 and 2020 included distal radius fracture $(-34)$, ankle fracture ($12)$, metacarpal fracture (-14) and phalynx fracture (-15). This observation reflects our hypothesis for the rise in distal femur +/- periprosthetic injuries was the elderly cohort performing more relatively risky activities of daily living they otherwise would not have performed with more help and aid in a nonlockdown environment and a reduction in sports related injuries.

\section{Mechanisms}

Fall from standing height was the predominant mechanism in each year but dropped by 68 overall. Mechanisms that did not appear in the top 10 in 2020 compared to 2019 due to lockdown included punching, football and hyperextension mechanisms which are to be expected given the cessation of sports and bars being closed. Overall numbers for these 3 mechanisms reduced from 21,10 and 9 to 0,1 and 0 respectively. Those that increased included pathological, fall. $0.5 \mathrm{~m}$, fall of a step, fall $>3 \mathrm{~m}$. Those that remained static included fall $>1 \mathrm{~m}, \mathrm{RTC}$, fall $>4 \mathrm{~m}$ and seizure. Mechanisms which appeared in our top 10 in 2020 but not in 2019 included RTC but overall numbers didn't change in comparison to 2019 and remained at 8 . This was surprising however given less traffic on the road with lockdown but potentially people were taking more risk when driving for e.g. driving faster given less traffic. Other mechanisms included fall $>3 \mathrm{~m}$ increased by 1 in 2020 to 6 and again this was despite the dramatic reduction in numbers we seen. We felt men were performing DIY activities at home at height they would not have otherwise been performing due to lockdown to fill the increased time spent at home.

\section{Operations}

Change in operative management reflected the types injuries presenting between the 2019 and 2020 observed periods. There was an increase in DHS $(+15)$, Radial head surgery - replacement or $\operatorname{ORIF}(+6)$, tension band wiring olecranon(+5), Distal femur ORIF(+5).
Operations with no change in amount performed between 2019 and 2020 observational period included tibial nailing, tendon repairs, external fixations of fractures, foreign body removals, and hind foot nailing. Operations which decreased during observed period included; distal radius surgery - $\mathrm{k}$ wire or ORIF (-2)7, metacarpal ORIF(-12), neck of humerus ORIF $(-9)$, scaphoid ORIF (-9), conversion of external fixation to $\operatorname{ORIF}(-9)$.

There was a change in practice which reflects a move away from total hip replacement (THR) in favour of hemiarthroplasty during Covid times with a drop in THRs from 13 to 6 despite similar presentations of hip fractures in general. In keeping with BOAST guidance to manage fractures in the correct way this data may imply a move to the most limited operative management required for fracture management during Covid times.

\section{Conclusion}

These findings show the impact a government-imposed lockdown as a result of the Covid-19 pandemic has had on trauma and orthopaedic services within the Southern Trust in Northern Ireland. Service delivery was rapidly adjusted according to guidance to maximise patient and staff safety but in a way in which also supported ongoing emergency trauma care. Our study highlights how fracture presentations requiring admission and operative management of same during the first three months of the pandemic contrasted to the same time period one year prior.

Learning points for this study are that the writers hope that this paper can be used to advise teams locally and nationally to adapt their services accordingly in the event of further local or regional lockdowns.

This paper aims to advise trusts with a comparable cohort of patients to the Southern Trust on how trauma services may need to be adjusted in order to cope with the constraints of local or national lockdowns while also trying to deliver a safe trauma service for both patients and staff.

\section{Acknowledgements}

- Rececca Mackey - Data collection.

- Jennifer Corner -Data collection.

- Rachel McCauley -Data collection.

\section{Data Collaborators - Mackey R, Corner J, McCauley R}

\section{References}

1. Rothan HA, Byrareddy SN (2020) The epidemiology and pathogenesis of corona virus (Covid-19) outbreak. J Autoimmun 109: 1-4.

2. Coimbra R, Edwards S, Kurihara H, Bass GA, Balogh ZJ, et al. (2020) European Society of Trauma and Emergency Surgery (ESTES) recommendations for trauma and emergency surgery preparation during times of COVID-19 infection. Eur J Trauma Emerg Surg [Internet] 46: 505-510.

3. British Orthopaedic Association. Management of patients with urgent orthopaedic conditions and trauma during the coronavirus pandemic. 2020: 1-6.

4. NHS England (2020) Clinical guide for the management of trauma and orthopaedic patients during the coronavirus pandemic. Spec Guid patient Manag Dur coronavirus pandemic [Internet] 1: 1-5. Available from:

\section{https://sogacot.org/wp-}

content/uploads/2020/03/specialty-guideorthopaedic-trauma-and-coronavirus-v1-16-march2020.pdf

5. NHS (2013). When to use a surgical face mask or FFP3 respirator. 2013;2901107. Available from: https://www.rdash.nhs.uk/wpcontent/uploads/2017/08/Appendix-47-Surgical- 
Face-Mask-FFP3.pdf

6. Rodrigues-Pinto R, Sousa R, Oliveira A (2020) Preparing to Perform Trauma and Orthopaedic Surgery on Patients with COVID-19. J Bone Joint Surg Am 102: 946-950.

7. Hampton M, Clark M, Baxter I, Stevens R, Flatt E, et al. (2020) The effects of a UK lockdown on orthopaedic trauma admissions and surgical cases. Bone Jt Open 1: 137-143.

8. Fahy S, Moore J, Kelly M, Flannery O, Kenny P (2020) Analysing the variation in volume and nature of trauma presentations during COVID-19 lockdown in Ireland. Bone Jt Open 1: 261-266.
9. Thornton J (2020) Covid-19: A\&E visits in England fall by $25 \%$ in week after lockdown. BMJ [Internet] 369(April):m1401.

10. Christey G, Amey J, Campbell A, Smith A (2020) Variation in volumes and characteristics of trauma patients admitted to a level one trauma centre during national level 4 lockdown for COVID-19 in New Zealand. N Z Med J [Internet] 33: 81-88.

11. Mueller M, Boettner F, Karczewski D, Felix S, Kramer A, et al. (2020) Dealing with the COVID-19 pandemic in orthopaedics: experiences and procedure in Germany. Bone Jt Open1: 309-315.

Citation: Matthews S, McGoldrick P, Khan R, Bunn J (2021) COVID-19 Pandemic - Impact to Trauma and Orthopaedic services in a Northern Ireland District General Hospital. Adv Ortho and Sprts Med: AOASM-140. 